\title{
Societal Costs of Diabetes Mellitus 2025 and 2040 - Forecasts Based on Real World Cost Evidence and Observed Epidemiological Trends in Denmark
}

\author{
Camilla Sorts $\emptyset^{1 *}$, Martha Emneus ${ }^{2}$, Anders Green ${ }^{3}$, Peter Bjødstrup Jensen³, \\ Thomas Eriksson 4 \\ ${ }^{1}$ Centre of Health Economics Research (COHERE), Department of Business and Economics, \\ University of Southern Denmark, Copenhagen, Denmark \\ ${ }^{2}$ Institute of Applied Economics and Health Research (ApEHR), Copenhagen, Denmark \\ ${ }^{3}$ Odense Patient Data Explorative Network (OPEN), Odense University Hospital, \\ University of SouthernDenmark, Copenhagen, Denmark \\ ${ }^{4}$ Institute of Applied Economics and Health Research (ApEHR), Copenhagen, Denmark \\ Email: ${ }^{*}$ caso@sam.sdu.dk
}

Received 17 September 2015; accepted 27 October 2015; published 30 October 2015

Copyright (C) 2015 by authors and Scientific Research Publishing Inc.

This work is licensed under the Creative Commons Attribution International License (CC BY). http://creativecommons.org/licenses/by/4.0/

(c) (i) Open Access

\begin{abstract}
Aim: The objective is to contribute with real world evidenced economic forecasts of diabetes attributable costs in $\mathbf{2 0 2 5}$ and $\mathbf{2 0 4 0}$ differentiated according to patients' morbidity status which is a novel approach within forecasting. Methods: Method of forecasting is based on an annual calendar year prediction of diabetes attributable costs by using the BOX-model, an established and tested epidemiological transition-state model. The study population includes all Danish diabetes patients presented in $2011(N=318,729)$ according to the Danish National Diabetes Register. Forecasting is based on individual patient data from 2000 to 2011 for incidence, mortality, patterns of morbidity and complication rates combined with demographic population projections from Statistics Denmark. The 2011 estimation of diabetes attributable costs were applied to the epidemiological framework. Forecasting was performed for three different epidemiological scenarios.Results: Our three epidemiological scenarios indicate that within the shorter time span increases in the prevalent population are difficult to change primarily due to the already achieved historic improvements in diabetes mortality and morbidity. These will approximately double societal costs of diabetes in the next 10 years,assuming current trends in morbidity and mortality are maintained.The resulting diabetes population will incur three times current costs in $2040 . \mathrm{A} \mathrm{20 \%}$ re-
\end{abstract}

\footnotetext{
${ }^{*}$ Corresponding author.
}

How to cite this paper: Sorts $\varnothing$, C., Emneus, M., Green, A., Jensen, P.B. andEriksson, T. (2015) Societal Costs of Diabetes Mellitus 2025 and 2040-Forecasts Based on Real World Cost Evidence and Observed Epidemiological Trends in Denmark. Modern Economy,6, 1150-1166. http://dx.doi.org/10.4236/me.2015.610109 
duction in cost per PYRS shows how the relative distribution of patients with complications is expected to change over time with patients living better with their disease and hence incur a lower demand for health and nursing care services.

\section{Keywords}

Forecasts, Cost of Illness, Diabetes Mellitus, Health Care Costs, Register Research, Societal Costs

\section{Introduction}

Chronic diseases are one of this century's greatest threats towards public health with almost epidemic prevalence increases globally and expectations of significant increases in the future [1]. Diabetes Mellitus is, with around 350 million people globally suffering from this disease [2] [3], one of the most burdensome chronic diseases associated with major disability, reduced quality of life and shortened length of life [2] [4].

Various factors are expected to cause future increase in the prevalence of diabetes: demographic changes[5], sedentary life styles and obesity [6]-[8], improved survival [9] [10] epidemiology [11], screening efforts [12] and new morbidity patterns implying that diabetes is increasingly seen in younger ages [13] [14]. Management of the increasing diabetes population implies, among others, an economic challenge, which societies must face, as diabetes patients require increased health care, pharmaceuticals and nursing services for their remaining lifetime[4] [15] [16]. Long term models can identify where a society may be heading, providing policy makers with a foundation on which decisions concerning future strategic prioritization can be grounded [17].

Forecasts of the burden of diabetes exist in great numbers in the literature, see for example, King et al. 1998 [18],Bagust et al. 2002 [19], Huang et al. 2009 [20], Mainous et al. 2007 [21] or Tunceli et al. 2009 [22]. Our forecasting model (the BOX-model) is an established and tested epidemiological disease model, which has proven its global applicability for different diseases with largely accurate predictions showing only nonessential deviations[9] [23] [24]. The BOX-model is simple and intuitive, based on epidemiological drivers observed over more than a decade and economic cost estimates for 2011 calculated on the individual level from national registers.

Based on a comprehensive epidemiological framework, this study forecasts diabetes attributable costs in Denmark for the period 2012-2040 according to sectors and patient's morbidity status. Denmark has optimal conditions due to data availability, coverage of the diabetes population and richness of information in national registers [25]. In addition, Denmark is a typical European country in terms of treatment availability and population structure. The study was part of a large-scale register based on observational investigation, the Diabetes Impact Study 2013 [26], which investigated epidemiological, health economic and socioeconomic aspects of diabetes in Denmark [11] [16] [27].

\section{Method}

Estimating the size of future costs attributable to diabetes, the epidemiological dynamics underlying the prevalence of diabetes must be taken into account. Each year, new patients are diagnosed, patients develop complications and yet other patients will die. These dynamic structures are appreciated in the forecasts through the underlying epidemiological framework, presented in the BOX-model.

\subsection{The BOX-Model}

To model the future prevalent diabetes population, this study uses a simple multi-state transition model, the BOX-model, a flexible epidemiological framework, based on individual data from the entire Danish diabetes population. The BOX-model, (Figure 1) has been validated [9] and thoroughly described elsewhere [11].

In the BOX-model, an individual is either non-diabetic (population at risk) or belongs to one of the diabetic complication groups: CG0, no complications; CG1, minor complications or CG2, major complications. ICD-codes defined for each complication group is given in the supplementary material (A). Health states in the model are mutually exclusive and collectively exhaustive meaning that each patient can only be in one state in a cycle and must be in a state in each cycle. Cycles are measured in calendar years [28]. Irreversibility is assumed and,therefore, 
The BOX model of the dynamics of a disease:

A chronic disease with stratification by complication

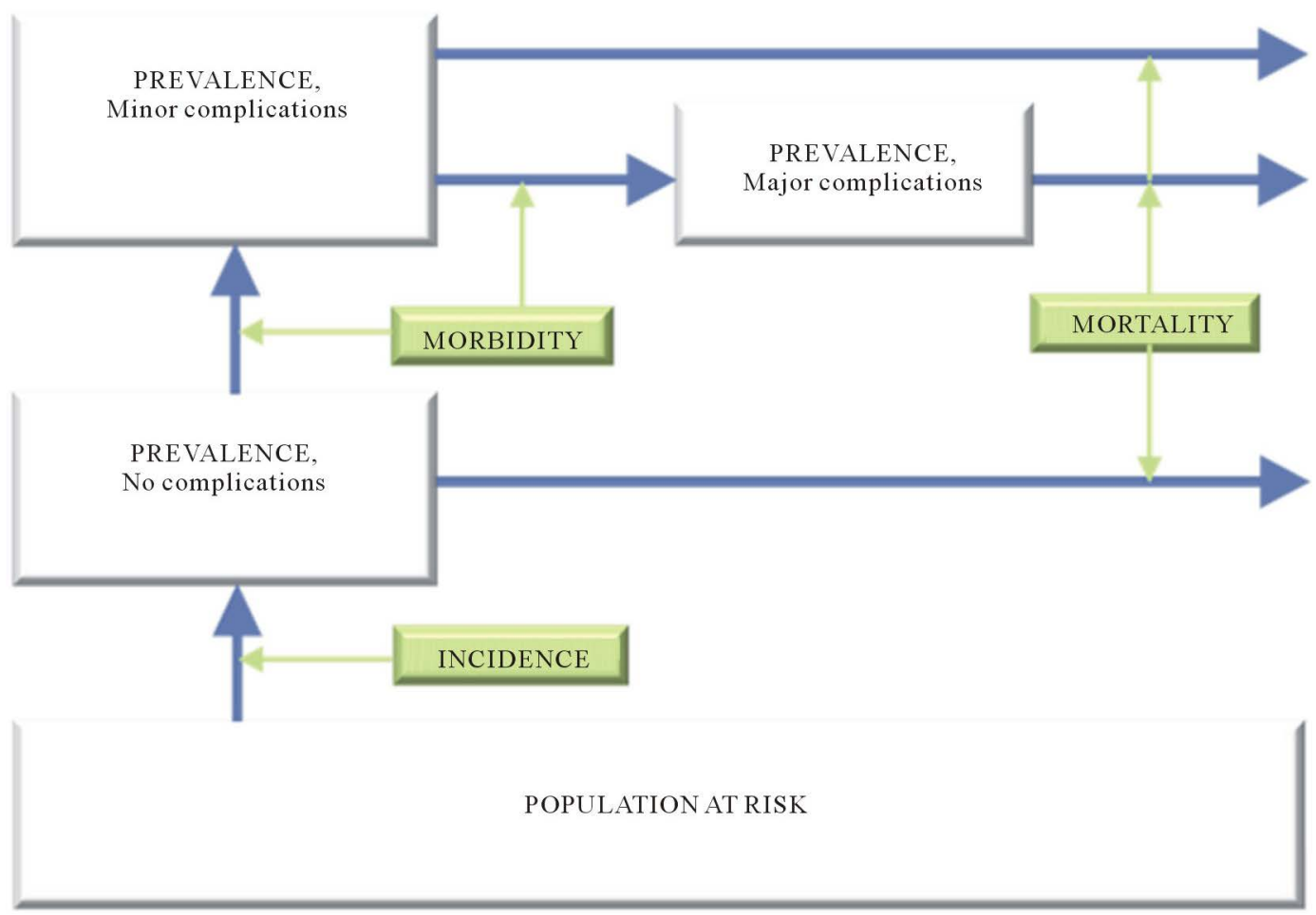

Figure 1. The BOX-model.

patients can only move forward in the model. Influx (new incident cases) and outflux (mortality) as well as influx to each of the complication groups were accounted for on an annual basis. Forecasting is based on patient groups defined by gender and age at diagnosis in 25 year age intervals.

\subsection{Study Population}

The study population was based on the entire diabetes population in Denmark in 2011, adjusted according to shortcomings in the Danish National Diabetes Register, specified elsewhere [29], $N=318,729$. Person years (PYRS), defined as 365 person days, $N=297,378$ in 2011 were applied. The study population was compared to the Danish diabetes-free population $(N=5,261,714)$ and to a matched (gender, age and municipality of residence) control population from the diabetes-free population $(N=1,462,872)$.

\subsection{Data Sources for Epidemiological Forecasting}

The epidemiological forecasting was based on observed individual patient level data on the entire Danish diabetes population from 1997 through 2011 through Danish national registers [11]. Transition probabilities between states were extrapolated from the observed data resulting in a prevalence (PYRS) in each health state in every calendar year. This means that the exact number of projected PYRS in 2011 deviates from the observed number, however the deviation is $<1 \%$. To facilitate comparison with earlier studies [11] [16] [27], we state the observed numbers from 2011. PYRS were stratified by gender and age at diagnosis in 25 year age intervals. The diabetes-free population, and hence population time at risk of developing diabetes, for each calendar year until 2040 was calculated from demographic population projections from Statistics Denmark based on recent trends for vital demographic events: birth rate, death rate, immigration, emigration and naturalization, converging towards a long time perspective level based on annual forecasts [29]. This epidemiological forecasting make up 
the framework on which 2011 cost estimates are added.

\subsection{Data Sources for Economic Forecasting}

Age at diagnosis, gender and complication status, among other characteristics, influence on patients costs [16]. Estimates for diabetes attributable costs according to these characteristics were calculated and applied to the epidemiological model.Diabetes attributable costs for 2011 were calculated as the difference between total costs of a person with diabetes and the expected total costs given the annual resource consumption of the control population stratified according to gender and five-year age intervals. The included cost components are listed in Table 1 along with measurement of cost components and described in more detail elsewhere [16].

Table 1. Cost components, cost units and method of calculation.

\begin{tabular}{ll}
\hline Cost component & Cost unit and method of calculation \\
\hline $\begin{array}{l}\text { Inpatient and outpatient services delivered } \\
\text { in Danish hospitals registered in DNPaR }\end{array}$ & $\begin{array}{l}\text { Diagnosis Related Grouping system tariffs, year 2012 [30].The } \\
\text { DRG tariff system is developed for administrative purposeand } \\
\text { based on rough average costs across hospitals for specific } \\
\text { diagnostic groups. Excludes interest and depreciation of buildings } \\
\text { and equipment while other overhead costs are included. }\end{array}$ \\
\hline
\end{tabular}

Primary care services delivered by general practitioners andprivately practicing specialists such as: dentists, physiotherapists, chiropractors and chiropodists who are registered in DNHSR
Reimbursement fees between the National Health Insurance scheme and private practicing physicians are used as cost units. General practitioners are compensated by regions through a combination of per capita fee (app.30\% of total) and fee for service (app. 70\%) [31]. To reflect this payment scheme in the unit cost, $43.8 \%$ of the fee for service in general practice was added on top. Overhead costs covered by capitation fee were, hence not distributed across numbers of visits, as would have been most appropriate, but by resource burden.

Total Sales Price (TSP) includes patient Out of Pocket Payments (OPP), since costs of prescribed pharmaceuticals are shared between the patient and the primary health care sector by a copayment scheme, where patients are reimbursed according to their need. These costs were aggregated, since total costs are measured regardless of who pays. While pharmaceutical consumption includes value added tax (VAT), Danish health care services are exempted from VAT. Given that VAT is 25\% in Denmark, 20\% of pharmaceutical consumption was subtracted to get comparable net costs.
Costs of living in a nursing home/sheltered accommodation

Based on individually registered address in SD
Unit cost was calculated as total annual costs of running these facilities divided by the number of inhabitants, 51,486 DKK (exclusive of capital costs) per person living in nursing homes per year. Hereto was added average number of hours of nursing received by persons living at nursing homes or sheltered accommodation calculated by SD equal to 18.6 hours per week per person or 565,283 DKK applying a unit cost of 588 DKK per hour. In total 616,769 DKK per person per year. The cost unit included overhead and administration but not capital costs.

Registrations on volume of services were, incomplete whereas whereas number of individuals receiving care appeared rather completely registered. Therefore, national volume estimates from SD were applied together with the number of $\mathrm{PwD}$ receiving care compared to the expected number given the observed frequency among the diabetes-free population, in gender and age strata, to estimate the amount of nursing services received attributable to diabetes. Average number of hours of nursing received by persons living in their own home was estimated to be 3.6 hours. The unit cost was defined as average costs for one hour of nursing delivered in the given year (calculated as the total costs for nursing divided by number of hours of care delivered in the year),based on data published by SD, equal to 588 DKK per hour.
Home nurse visits per year based on individual registrations in SD
Number of visits by home nurse appeared rather completely registered on an individual basis. Unit cost was calculated as average costs for home nurses per inhabitant times the Danish population divided by the total number of services,based on data published by SD.One service is estimated to be 456 DKK. 


\section{Continued}

Productivity loss based on data from SD
SMBG costs (meters and sticks)

and insulin pumps
Lost productivity attributable to diabetes were accounted for through an estimation of 1) Annual mean gross income difference from expected income given educational level, gender and age; 2) Premature mortality; 3) Abseentism.

1) Sum of absolute difference in annual gross income between PwD and controls aggregated for patients older than 14 years and younger than 69 in strata by gender, age in 5 year intervals and four educational levels $(1:<11$ years of education; 2: $<16$ years; $3:<18$ years and 4: 18+ years)

2) Sum of annual foregone income due to lost years of productivity in cases of premature death for: 2a) 2011 and 2b) productivity loss in 2011 due to deaths attributable to diabetes occurred prior to 2011. Since data is not available on deaths attributable to diabetes for the past 45 years, we used attributable deaths in 2011 and the production loss that will incur in the future until the age of 69 to mirror the foregone production well knowing that this method builds on the simplified assumption that diabetes mortality and labour market patterns the past decades have not changed. For persons between the age of 15 and 69, number of relative deaths by gender and 10-year age group was compared between PwD and controls and the difference is assumed to represent deaths attributable to diabetes. Number of attributable deaths in each strata was multiplied with the average wage of a diabetes-free person in that strata. 2a) Strata were aggregated and the sum was divided by 2 assuming deaths are equally spread over the entire calendar year. 2b) Mid age in each age-interval was used as proxy and then number of years until the age of 69 was calculated and multiplied with number of attributable deaths in the given strata again multiplied with the average annual gross income among a diabetes-free person in that strata.

3) Number of days of absence due to diabetes is calculated based on literature estimates of 3 extra days a year. Daily wage is calculated as the mean annual income among PwD divided by 200 working days.

Cost of SMBG (for the 22\% of PwD using insulin) was estimated on the basis of a study of SMBG costs in Canada to annually 860 US\$ equivalent to 6175 DKK (2011 prices) [32].

According to the Danish Ministry of Health and the Danish Diabetes Association [33] pumps were used by approximately $2100 \mathrm{PwD}$ and the annual cost ranged from 22,000 to 39,000 DKK in 2010. For 2011,we have applied a conservative cost estimate of 22000 DKK for $80 \%$ of all T1 children ( $0-14$ year) and for $5 \%$ of the rest of the T1 population in total amounting to $2450 \mathrm{PwD}$. Censors are not included in this cost and would approx. double the annual cost of pumps.

Appliances (blind assistance, protese crus, femur, wheel chairs, sticks)
Unit costs of blind assistance was calculated on the basis of the MTV report [34]and includesassistance outside home, sticks and guide dogs, IT solutions for blind parents, blind library appliances and amounted to 99,137 DKK per year (2011 prices). The cost cover needs for the $1.1 \%-1.6 \%$ (amounting to approx. 3372 persons) of the diabetes population that is considered socially blind [34].

The cost of a crus and femur prosthesis was estimated to be respectively 17,000 and 44,000 DKK per year. In 2011, 1348 (crus) and 768 (femur) persons with diabetes lived with an amputation and respectively $75 \%$ and $50 \%$ of those were assumed to have a prosthesis. The rest of the amputated persons are assumed to use wheel chairs.

The cost of wheel chairs was calculated from an average of different chair types (ranging from a cost of 2,589 to 34,109 DKK) [35]to an annual average cost of 2,450 DKK. $25 \%$ of diabetes patients (above 45 years) with complications are assumed to need a wheel chair.

A total of 4 hours per diabetes patient under 29 years (3\%) and all persons diagnosed during 2011 (10\%) and 1 hour for $50 \%$ of the rest of the diabetic population was applied as an estimate of the received support in any of the following forms (prevention initiatives, educational training or psychological assistance, telemedicine etc.) An hourly cost of 588 DKK was applied.

According to an evaluation [36] [37] by diabetes educators, experienced diabetes patients controlled by oral agents would use 2 hours a day when asked to follow the American Diabetes Association self-care recommendation and elderly and handicapped patients would use more. Exercise and diet, required for self-care of many chronic conditions, are the most time-consuming tasks. We included a conservative estimate of patients' time ( 1 hour per week per patient) and informal caregivers' time (8 hours per year per patient) at a cost of $25 \%$ of the productive value.

Data on costs of capital depreciation in secondary care and for nursing services were included with $20 \%$ of secondary care and nursing costs. 
Given that cost estimates for the year 2011 were originally calculated according to age in five year intervals,these estimates were recalculated to age at diagnosis in 25 year age groups. Due to data limitations, this recalculation was not possible for nursing services and additional cost components. Therefore, we applied the same cost structure between age and age at diagnosis for these two cost components as found for health care costs. Furthermore, we maintained total attributable cost estimates calculated on age groups and applied the estimated cost structure between age and age at diagnosis across strata based on these totals. Cost calculations of productivity loss due to premature mortality were calculated based on assumptions concerning the mortality rate. Hence, the model considers the annual assumed mortality rate and adjusts productivity loss due to premature mortality correspondingly. Calculation of depreciation of capital was based on the size of the secondary health care sector cost component. All costs were calculated in fixed 2011 values.

\section{Scenarios}

Comparison between three contrasting scenarios was deployed. Each scenario was related to the same base year (2011) and outlines a situation specified according to observed epidemiological trends in incidence, mortality and complication progression from 1997-2011. The three scenarios represent: 1) continuation of observed epidemiological trends under the assumption that these trends will continue as historically observed (core); 2) continuation of the observed trends regarding mortality and complication rates but a constant rate of incidence as observed in 2011, reflecting the assumption that incidence will stabilize and discontinue the increase (intermediate); 3) all epidemiological drivers are kept constant on the level observed in 2011 to reflect no further improvements in mortality and morbidity among diabetes patients and no further incidence increase (constant). Scenarios are presented in Table 2.

For each scenario, the BOX-model calculates a distribution of PYRS. By adding estimates of diabetes attributable costs specific for gender and age at diagnosis, total diabetes attributable sector costs for every calendar year are arrived at.

Table 2. Epidemiological scenarios.

\begin{tabular}{l|l|l|}
\hline \multicolumn{1}{c|}{ Scenario } & \multicolumn{1}{c}{ Drivers } & \multicolumn{1}{c}{ Description } \\
\hline $\begin{array}{l}\text { Core } \\
\text { Continuation of trends }\end{array}$ & Incidence & $\begin{array}{l}\text { Continuation of 2001-2011 observed } \\
\text { increasing trend }\end{array}$ \\
\cline { 2 - 3 } & Mortality & $\begin{array}{l}\text { Continuation of 2001-2011 observed } \\
\text { decreasing trend until X }\end{array}$ \\
\cline { 2 - 3 } & Complication rate transitions & $\begin{array}{l}\text { Continuation of 2001-2011 observed } \\
\text { trends: reduction in transition from } \\
\text { CG0 to CG1 and CG2 until X }\end{array}$ \\
\hline $\begin{array}{l}\text { Intermediate } \\
\text { continuation of trends in } \\
\text { morbidity and mortality }\end{array}$ & Incidence & Stabile rate as observed in 2011 \\
\cline { 2 - 3 } & Mortality & $\begin{array}{l}\text { Continuation of 2001-2011 observed } \\
\text { decreasing trend until X }\end{array}$ \\
\cline { 2 - 3 } & Complication rate transitions & $\begin{array}{l}\text { Continuation of 2001-2011 observed } \\
\text { trends: reduction in transition from } \\
\text { CG0 to CG1 and CG2 until X }\end{array}$ \\
\hline $\begin{array}{l}\text { Constant } \\
\text { Continuation of } 2011 \text { level }\end{array}$ & Incidence & Stabile rate as observed in 2011 \\
\cline { 2 - 3 } & Mortality & Stabile rate as observed in 2011 \\
\cline { 2 - 3 } & Complication rate transitions & Stabile rate as observed in 2011 \\
\hline
\end{tabular}

\section{Economic Potentials}

The cost forecasts mirror the observed cost structure and level in 2011, though it is obvious that the future will not hold the same investments and treatment/cost structures as in 2011. A prerequisite for the proposed epidemiological scenarios is, therefore, to capture some structural changes and potential relevant investment cases. On the one hand, the continuation of treatment improvements as assumed in scenarios (core and intermediate) cannotbe 
expected without some future investments in pharmaceuticals and health care. On the other hand, the cost levels in health care, nursing and pharmaceuticals will ultimately be decided, by what is politically possible in the years to come. Hence, the challenge is to quantify implications hereof for the cost forecasts. To accommodate this in our model, we suggested a number of hypotheses representing, on one hand, potentials for freeing of resources if certain efficiency improvements are realized or of a given political or administrative initiative and, on the other hand, budget limitation or economic potentials of a given investment. Based on the Core scenario each of the hypotheses was estimated under the assumption of everything else held constant.

Hypotheses, rationale and corresponding model adjustments are described in Table 3 and Table 4.

Table 3. Description of hypotheses, rationale and model adjustment method: economic potential of investments.

\begin{tabular}{|c|c|c|}
\hline Hypothesis & Rationale & Model adjustment method \\
\hline \multicolumn{3}{|c|}{ Economic potential of a given investment } \\
\hline $\begin{array}{l}\text { H1: Increased investments } \\
\text { in primary care }\end{array}$ & $\begin{array}{l}\text { Focus on patient self-care initiatives and improved } \\
\text { health among patients with diabetes can be expected } \\
\text { to move patients from secondary to primary care. }\end{array}$ & $\begin{array}{l}5 \% \text { annual increase in costs per } \\
\text { PYRS in primary care }(200 \% \\
\text { increase in 2040) }\end{array}$ \\
\hline $\begin{array}{l}\text { H2: Increased investments } \\
\text { in pharmaceuticals }\end{array}$ & $\begin{array}{l}\text { Investments in new and better pharmaceuticals plus a } \\
\text { more proactive medication of PwD can be expected } \\
\text { to increase pharmaceutical costs. }\end{array}$ & $\begin{array}{l}\text { 2.5\% annual increase in costs } \\
\text { per PYRS for pharmaceuticals }\end{array}$ \\
\hline $\begin{array}{l}\text { H3: Increased investments } \\
\text { in secondary prevention such } \\
\text { as telemedicine }\end{array}$ & $\begin{array}{l}\text { Telemedicine for patients with chronic diseases as } \\
\text { diabetes are in rapid development [38] [39]. Investments } \\
\text { in telemedicine have the potential to reduce patients' need } \\
\text { for health care services and improve their daily regulation. } \\
\text { Increased investments in secondary prevention to increase } \\
\text { self-management can be expected to improve the regulation } \\
\text { of diabetes patients, who have not yet developed } \\
\text { complications from their disease. }\end{array}$ & $\begin{array}{l}\text { 2.5\% annual increase in cost } \\
\text { per PYRS for } \\
\text { - H3a SMBG } \\
\text { - H3b patient education } \\
\text { - H3c patients' own time for } \\
\text { managing their disease }\end{array}$ \\
\hline
\end{tabular}

Table 4. Description of hypotheses, rationale and model adjustment method: potential for freeing of resources of a given initiative.

\begin{tabular}{|c|c|c|}
\hline Hypothesis & Rationale & Model adjustment method \\
\hline \multicolumn{3}{|l|}{$\begin{array}{l}\text { Potential for freeing of } \\
\text { resourcesof a given political } \\
\text { oradministrative initiative }\end{array}$} \\
\hline $\begin{array}{l}\text { H4: Efficiency improvements in } \\
\text { a) the health care sector } \\
\text { b) nursing services }\end{array}$ & $\begin{array}{l}\text { Annual productivity gains are achieved in the Danish } \\
\text { health care sector/nursing sector. In the period 2003-2011, } \\
\text { the annual productivity gains in the Danish health care } \\
\text { sector has been } 2.3 \% \text { and in } 2011 \text { alone } 5.3 \% \text { [40]. }\end{array}$ & $\begin{array}{l}\text { Annual } 1 \% \text { reduction of costper } \\
\text { PYRS for } \\
\text { H4a-primary andsecondary care } \\
\text { H4b-all nursingcomponents }\end{array}$ \\
\hline $\begin{array}{l}\text { H5: Reduced usage of } \\
\text { nursing services }\end{array}$ & $\begin{array}{l}\text { Patients with diabetes live longer and better with their } \\
\text { diabetesand in comparison with } 2006 \text { estimates, the } \\
2011 \text { cost structureimplies relatively less costs fornursing } \\
\text { [16]. This can also be aconsequence ofstructural changes } \\
\text { in the Danish nursing sectorwith reduced services. If these } \\
\text { developments are continued, theneed for/usage of nursing } \\
\text { services per PYRS can be expectedto further decrease over } \\
\text { time. The number of nursing homesand similar housing for } \\
\text { elderly in } 2011 \text { have decreased with } 62 \% \text { of the level in } \\
2005 \text { [41]. }\end{array}$ & $\begin{array}{l}\text { Annual 2.5\% reductionperPYRS } \\
\text { in all nursingcost components }\end{array}$ \\
\hline $\begin{array}{l}\text { H6: Reduced usage of } \\
\text { secondary care services }\end{array}$ & & $\begin{array}{l}\text { Annual } 2.5 \% \text { reduction in costs } \\
\text { per PYRS in secondary care }\end{array}$ \\
\hline $\begin{array}{l}\text { H7: Reduced productivity } \\
\text { loss among patients in CG0 }\end{array}$ & $\begin{array}{l}\text { Improved regulation of diabetes patients who have not yet } \\
\text { developed complications from their disease. } \\
\text { If CG0 patients were able to contribute more equal to thediabetes- } \\
\text { free population on the labour market, productivitylosses due to } \\
\text { lower income and excess absence could bedecreased. }\end{array}$ & $\begin{array}{l}\text { Annual } 2.5 \% \text { reduction perPYRS } \\
\text { in productivity lossdue to difference } \\
\text { in annualincome and excess absence } \\
\text { for patients in CG0 }\end{array}$ \\
\hline
\end{tabular}

\section{Results}

All cost estimates are presented in 2011 EUR based on a conversion rate from DKK to EUR of 7.4647 DKK. 


\subsection{Total Attributable Costs of Diabetes 2011-2040-The Three Scenarios}

We have previously estimated total attributable costs of diabetes to the Danish society in 2011 to be at least 4.27 billion EUR, corresponding to 14,349 EUR per PYRS [16]. Forecasting estimates of total diabetes attributable costs and costs per PYRS for each cost component in the three epidemiological scenarios are presented for the years 2025 and 2040 in Table 5. More detailed specification of distribution of costs according to sectors and complication groups together with epidemiological indicators are given in supplementary material (B).

Table 5. Prevalence, total attributable costs and cost per PYRS 2011, 2025 and 2040 in three epidemiological scenarios.

\begin{tabular}{|c|c|c|c|c|c|c|c|}
\hline \multicolumn{2}{|l|}{ Scenarios } & \multicolumn{2}{|c|}{ CORE } & \multicolumn{2}{|c|}{ INTERMEDIATE } & \multicolumn{2}{|c|}{ CONSTANT } \\
\hline Prevalence & 2011 & 2025 & 2040 & 2025 & 2040 & 2025 & 2040 \\
\hline Total & 300.769 & 644.738 & 1.183 .630 & 564.781 & 862.623 & 516.239 & 660.102 \\
\hline Comp 0 & 166.327 & 372.443 & 708.091 & 320.497 & 504.314 & 270.745 & 320.276 \\
\hline Comp 1 & 57.415 & 123.738 & 219.485 & 112.333 & 171.215 & 106.545 & 139.486 \\
\hline Comp 2 & 77.027 & 148.557 & 256.055 & 131.951 & 187.094 & 138.949 & 200.340 \\
\hline Costs1.000 EUR & 2011 & 2025 & 2040 & 2025 & 2040 & 2025 & 2040 \\
\hline Health care & 725.464 & 1.431 .167 & 2.455 .206 & 1.286 .964 & 1.842 .157 & 1.315 .790 & 1.850 .934 \\
\hline Pharmaceuticals & 149.954 & 306.039 & 532.748 & 274.265 & 400.288 & 267.676 & 359.782 \\
\hline Nursing & 849.716 & 1.619 .462 & 2.706 .185 & 1.468 .785 & 2.063.159 & 1.544 .347 & 2.236 .536 \\
\hline Production loss & 1.750 .026 & 3.064 .095 & 4.923.290 & 2.746 .838 & 3.698.946 & 3.127 .798 & 4.207.509 \\
\hline Additional costs & 761.957 & 1.529 .690 & 2.638 .948 & 1.369 .600 & 1.974 .463 & 1.356 .548 & 1.849 .551 \\
\hline Total & 4.237.117 & 7.950 .453 & 13.256 .377 & 7.146.452 & 9.979 .014 & 7.576.581 & 10.452 .805 \\
\hline Costs1.000 EUR & 2011 & 2025 & 2040 & 2025 & 2040 & 2025 & 2040 \\
\hline CG 0 & 1.000 .176 & 2.136 .663 & 3.976 .832 & 1.848 .713 & 2.829 .577 & 1.653 .206 & 1.942 .922 \\
\hline CG 1 & 780.826 & 1.587.383 & 2.735 .883 & 1.452 .635 & 2.152 .001 & 1.486 .812 & 1.966 .886 \\
\hline CG 2 & 2.456 .116 & 4.226 .406 & 6.543 .662 & 3.845.104 & 4.997.437 & 4.436 .563 & 6.542 .998 \\
\hline Cost per PYRS & 2011 & 2025 & 2040 & 2025 & 2040 & 2025 & 2040 \\
\hline Health care & 2.412 & 2.220 & 2.074 & 2.279 & 2.136 & 2.549 & 2.804 \\
\hline Pharmaceuticals & 499 & 475 & 450 & 486 & 464 & 519 & 545 \\
\hline Nursing & 2.825 & 2.512 & 2.286 & 2.601 & 2.392 & 2.992 & 3.388 \\
\hline Production loss & 5.819 & 4.752 & 4.159 & 4.864 & 4.288 & 6.059 & 6.374 \\
\hline Additional costs & 2.533 & 2.373 & 2.230 & 2.425 & 2.289 & 2.628 & 2.802 \\
\hline Total & 14.088 & 12.331 & 11.200 & 12.653 & 11.568 & 14.676 & 15.835 \\
\hline \multicolumn{8}{|l|}{ Cost per PYRS } \\
\hline Comp 0 & 6.013 & 5.737 & 5.616 & 5.768 & 5.611 & 6.106 & 6.066 \\
\hline Comp 1 & 13.600 & 12.829 & 12.465 & 12.932 & 12.569 & 13.955 & 14.101 \\
\hline Comp 2 & 31.887 & 28.450 & 25.556 & 29.140 & 26.711 & 31.929 & 32.659 \\
\hline
\end{tabular}

In Figure 2and Figure 3 respective total cost estimates and cost per PYRS for the three contrasting scenarios until 2040 are presented.

The core scenario predicted the Danish Diabetes population to increase to 1,183,630 patients in 2040, nearly four times the level in 2011, if current trends in incidence, mortality and complication progression were continued. This resulted in total diabetes attributable costs of 13.3 billion EUR in 2040 corresponding to 11,200 EUR per PYRS. The constant scenario, where all epidemiological indicators were held constant, resulted in the lowest prevalence and lowest total costs (660,102 patients and 10.5 billion EUR in 2040), however the highest costs per PYRS (15,835 EUR). This reflects that the core scenario assumes continued improvements in treatment results and hereby a less morbid, however, larger diabetes population where the constant scenario results in a smaller and more disease burdened diabetes population due to higher mortality and morbidity. Intermediate scenario was placed in between the two in respect to prevalence with 862,623 patients, but with the lowest total costs (9.98 billion EUR and more or less the same cost per PYRS as Core 11,568 EUR). Cost per PYRS decrease with time in both the core and the intermediate scenario as a result of the larger however less morbid diabetes population whereas an increase is seen in the constant scenario. The estimated total cost in 2025 are quite similar in the three scenarios ranging from 7.1 over 7.6 to 8.0 billion EUR varying hereby with less than $12 \%$ from the lowest to highest estimate reflecting the inertia of the future development in the diabetes population due tohistoric 


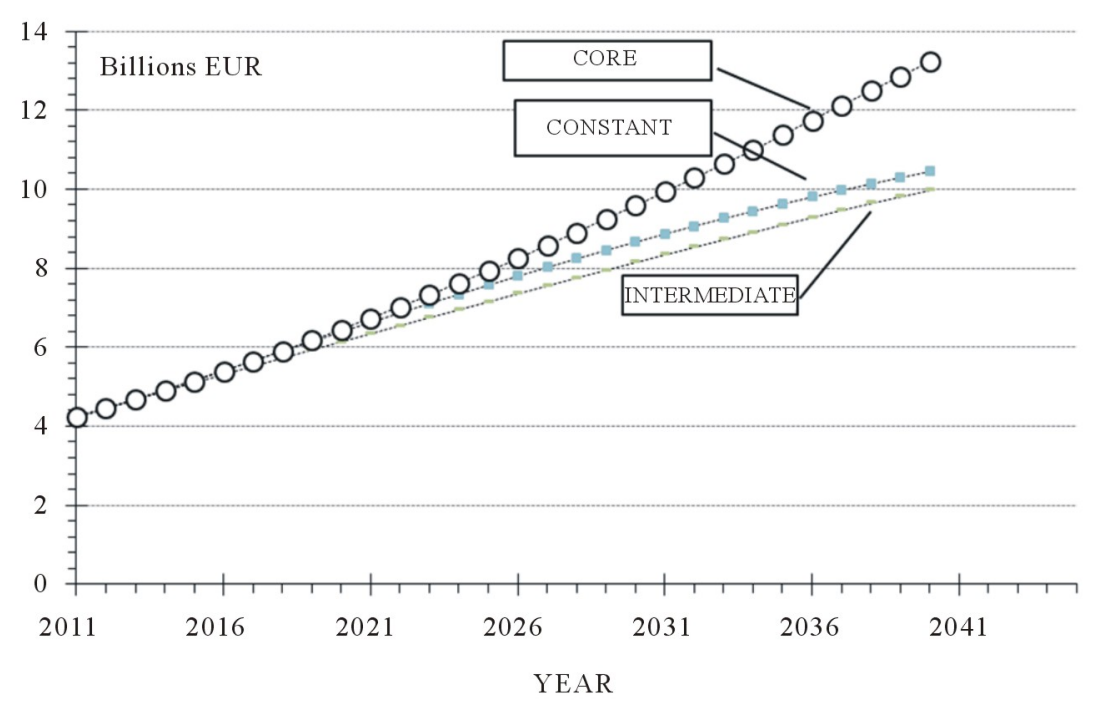

Figure 2. Total diabetes attributable costs 2011-2040 for the three epidemiological scenarios.

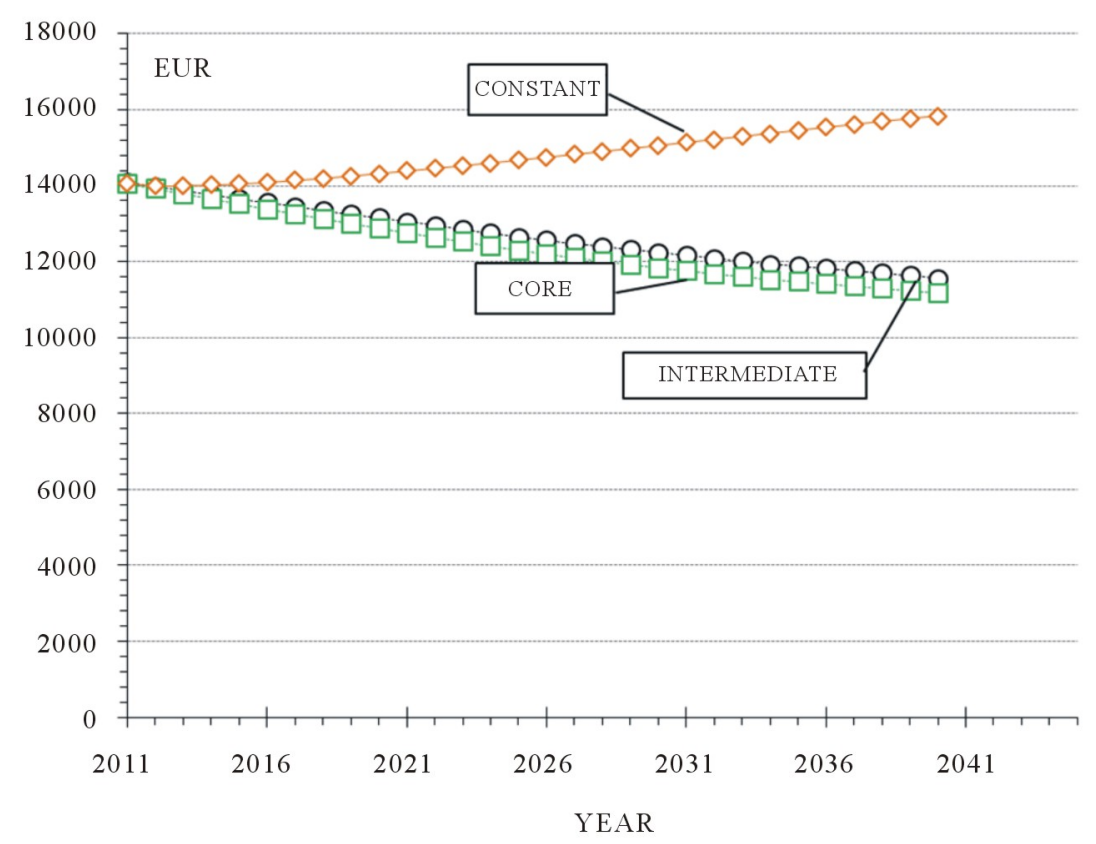

Figure 3. Cost per PYRS 2011-2040 for the three epidemiological scenarios.

developments and improvements in mortality and morbidity. Not much can be changed in the period up to 2025, while after 2025 the impact of different visions for trends setting from the year 2011 can be seen. For 2040, the range was 10.0 and 13.3 billion EUR representing a variation of maximum 33\%.

\subsection{Cost Distribution According to Sectors}

Looking at costs in the health care sector, these are projected to be between 1.8 and 2.5 billion EUR in 2040 (1.3 and 1.4 billion EUR in 2025). This is 1.8-2 times (2025) and 2.5- 3.4 times (2040) the current level in 2011. The same patterns are projected for pharmaceutical consumption and nursing services resulting in a demand for pharmaceuticals in 2040 of between 360 and 530 million EUR and a demand for nursing services in 2040 of between 2.7 and 3.4 billion EUR. 


\subsection{Cost Distribution According to Complication Groups}

Cost distributions within the three complication groups in 2011 and in 2040 across the three epidemiological scenarios are depicted in Figure 4.

The relative distribution of costs between complication groups were more or less similar in the core and the intermediate scenario, whereas a greater proportion of costs were spent among patients in CG2 in the constant scenario (63\% compared to relatively $49 \%$ and $50 \%$ ). This was mainly due to a greater volume of patients in CG2 in the constant scenario but also due to a steeper cost gradient from CG0 to CG2 in this scenario of 5.4 times higher cost in CG2 than CG0 compared to 4.6 and 4.8 times in the core and the intermediate scenario, respectively. In 2011 the $25 \%$ of patients with major complications consumed 58\% of the total resource use consumed by diabetes patients. The part of resource use consumed by patients with major complications decreases in 2040 in both the core and the intermediate scenario to app. 50\%, whereas it increases in the constant to the mentioned $63 \%$. The share of resources consumed by patients with no complications will respectively be $30 \%$ and $18 \%$ in the core and the constant scenario where CG0 will make up $60 \%$, compared to $49 \%$ of patients.

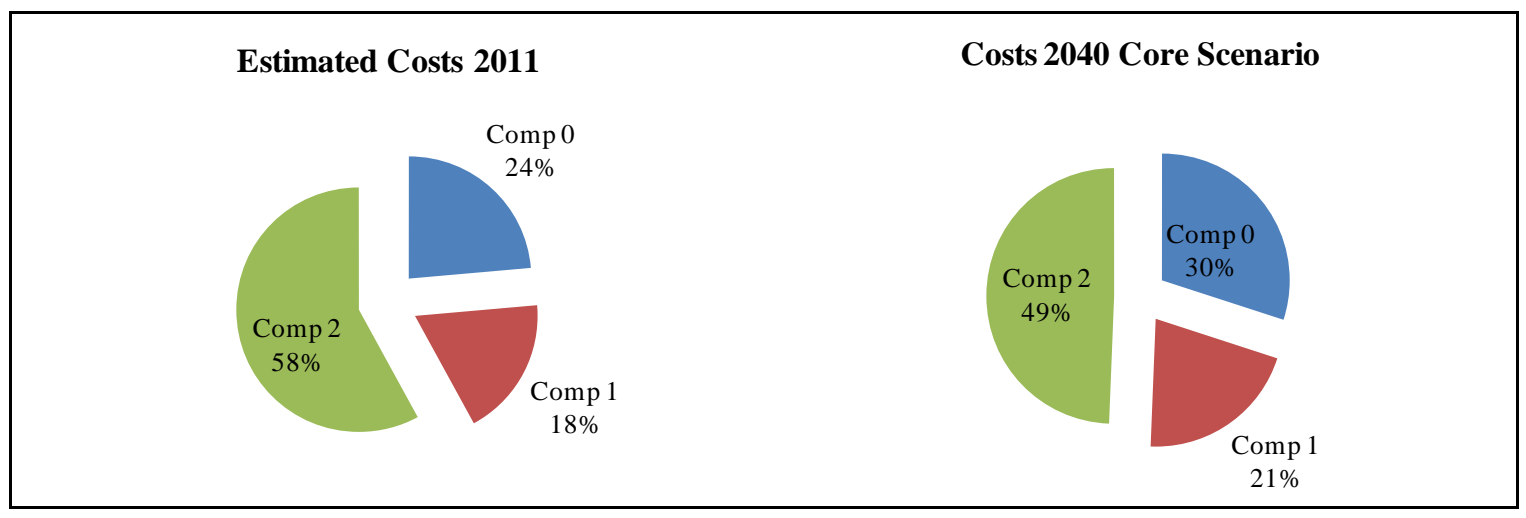

Costs 2040 Intermediate Scenario

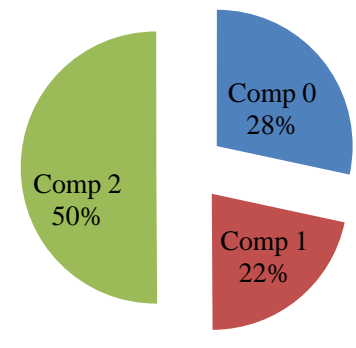

Costs 2040 Constant Scenario

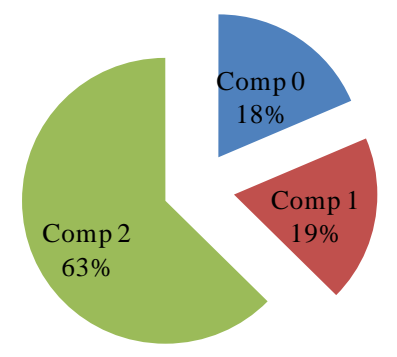

Figure 4. Distribution of diabetes attributable costs by complication group and epidemiological scenario.

\subsection{Economic Potentials}

To illustrate the understanding that future epidemiological development in the diabetes population would require some form of investment compared to the level of costs in 2011, we created some cases showing, on one hand, the level of economic resources that future investments require and, on the other hand, how economic space arefreed if certain efficiency improvements are realized. Important conclusions from these analyses were: If investments in primary care were set to increase with $5 \%$ annually (H1), investment in new pharmaceuticals with $2.5 \%$ annually (H2), and investment in secondary prevention with $2.5 \%$ (SMBG and Patient education) (H3a+H3b), the costs incurred by investments in 2025 will be in the range of 250 million EUR in 2025. In 2040 thecost (H1, H2, H3a+b) incurred will be 1.1 billion. If patients' own time (H3c) is included, 300 million EUR should be added for 2025 and 1.3 billion EUR for 2040 . 
If productivity increases by $1 \%$ per year in primary and secondary health care and nursing sectors 0.4 and 1.3 billion EUR would be freed in 2025 and 2040 respectively (H4a and H4b). If usage of secondary care services are reduced by $2.5 \%$ annually this will free resources in the range of 400 million EUR in 2025 and 1.2 billion EUR in 2040 (H5). For nursing services the corresponding numbers are 500 million and 1.4 billion EUR in 2025 and 2040 (H6). Reduced productivity loss (H7) among patients in CG0 of 2.5\% annually will free resources in the range of 280 million EUR in 2025, which is more than the sum of the suggested investments in primary care, pharmaceuticals and secondary prevention, when patients' own time are not taken into account. Results of each of the hypotheses are given in thesupplementary material $(\mathrm{C}+\mathrm{D})$.

\section{Discussion}

The point of departure for the forecasted scenarios are all centrally available data in Danish national health registers for all Danish diabetes patients in 2011 providing comprehensive estimates of real world evidenced costs attributable to diabetes forecasted according to 14 years of epidemiological data and a categorization of diabetes patients in three complication groups. This is a novel approach enabling an intuitive understanding of forecasting results as indicators of where diabetes, in a public health perspective, is heading. This study attempts to forecast trends in the future diabetes patient population and, hence, expected costs given the current resource consumption and productivity loss among diabetes patients. Model input are of highest possible quality, distinguishing the BOX-model from majority of international models based on data from population surveys, and the model has been validated showing only nonessential deviations[9] [23] [24]. Our analysis is distinct using societal attributable costs to diabetes including both resource consumption and productivity loss. Furthermore, we take into account the dynamics of diabetes and the expected natural history of disease in relation to development of late complications.

The BOX-model is general and intuitive aiming to guide decision makers as to where this disease is heading more than making accurate future projections. Trends from the forecasted scenarios may probably be generalized across countries. They indicate that increasing prevalence of diabetes and, hence, costs of diabetes are difficult to change within the shorter time span and will approximately double the next 10 years primarily due to the already achieved historic improvements in diabetes mortality and morbidity. Hereafter, the span is wider depending on the epidemiological trends occurring, however, it is realistic to assume a 2.5 or tripling of the patient population and, hence costs in 2040. Such estimates correspond well with international projections [20]. On the cost side, the predictions concerning health care, pharmaceuticals and nursing services are conditional on current rates of utilization and supply, which of course will change over time. From a societal perspective, the constant scenario can be viewed as a minimum cost under the assumption that 2011 cost structures and supplies are continued. This means that incidence rates are stable and no further progress in the health of diabetes patients in relation to morbidity or mortality occurs. This is probably unrealistic expectations, however,it sets the frame for comparison with the core scenario where the difference in costs (2.8 billion EUR in 2040) reflects the amount of extra resources necessary, if prevalence increases continues as observed until 2011. The intersmediate scenario compared to the core reflects the general public health expectation that primary prevention will result in stable or decreased incidence rates compared to historic trends. If this succeeds, a $25 \%$ reduction in costs can be expected in 2040 compared to the costs in the core scenario.

We believe that our estimations present intuitive understandable perspectives valuable for decision makers, for instance, for the health care system to be ready to meet this chronic disease challenge of a doubling in resource demand already in 2025 under current structures. With estimation of economic potentials to the core scenario, we aim to highlight how the scenarios can guide cost effectiveness discussions. For instance, interventions aiming to shift treatment of diabetes patients from secondary care to primary care can be compared to the threshold of around 500 million EUR in 2025 freed, if a goal of an annual 2.5\% decrease is reached. In comparison, a 5\% increased investment in primary care will cost an amount in the range of 45 million EUR in 2025. We do not argue for a given causal effect of a specific intervention, but merely point out the economic potentials if suggested goals were reached or specific investments were made.

Another important conclusion is that prevalence is a poor measure of disease control when it comes to chronic diseases. Lower cost per patient year might be more desirable than lower prevalence as this means that each patient is living better with his or her disease contributing to a larger prevalent population. Categorization of patients according to their complication status in three groups is a novel approach, which allows a more general view on the disease, which is easy to interpret and communicate. We have previously shown how health care 
costs and nursing costs increased markedly when patients with diabetes develop minor or major complications. Hence, there is great cost saving potential in preventing development of complications among patients with diabetes. This is reflected in the intermediate scenario, where focus is placed on efforts to sustain historic improvement in epidemiological indicators into the future, but incidence rates are assumed constant. We further project a shift in resource consumption from patients with major complications to patients without complications due to the volume of patients living with diabetes without complications in the future.

It must be stressed that the basic patient population in the scenarios has obtained its size and age composition as a consequence of access to diabetes treatment and care during decades prior to year 2001. Therefore, a comparison of PYRS experienced under competing scenarios reflects the cumulative effect of access to treatment over previous decades. In prolonging of this, it is important to bear in mind that costs are an expression of supply and demand meaning that patients' demand will only increase to the extent that the supply is available. In the model, discrete time intervals of one calendar year are used and not continuous time reflecting our wish for a simple and intuitive modeling approach. Age at diagnosis, and not running age, was used to reflect that the model follows a patient with diabetes from diagnose until death concerning age and gender specific costs and morbidity and mortality drivers. Forecasting 25 years ahead in time it is obvious that changes over time, in health care queues, waiting lists and treatment offers cannot be accommodated for in the model, as these are unknown. It is inevitable that modelers will make different choices and apply different assumptions. The included hypotheses can throw light on consequences of different assumptions, however, the model will never be a perfect representation of the real world [42].

\section{Conclusion}

Our projections indicate that within the shorter time span increases in the prevalent population, and therefore the associated cost, are difficult to change primarily due to the already achieved historic improvements in diabetes mortality and morbidity. These will approximately double societal costs of diabetes the next 10 years,assuming current trends in morbidity and mortality are maintained.The resulting diabetes population will incur three times the current costs in 2040, although the costs per PYRS are falling during the whole period.A 20\% reduction in cost per PYRS shows how the distribution of patients with complications are expected to change over time with patients living better and, hence, on average become less resource demanding with their disease. Prevalence is, therefore, a poor measure of disease control in a public health perspective. With marked increases in diabetes prevalence, not only resource demand for health care, nursing and pharmaceuticals will increase but also societal productivity loss due to the increasing number of patients in the working age.Despite wide uncertainty around projections of the future, they enable us to appreciate better the implications for societies of currently observed epidemiological trends. Hereby, projections provide a basis for discussing future resource demand and consequently the necessary investments and structural changes.

\section{Funding Sources}

This study has been conducted by ApEHR in cooperation with the Danish Diabetes Association and supported by a $\mathrm{PhD}$ program from COHERE, funded by The Danish Centre for Strategic Research in Type 2 Diabetes, DD2. A consortium of sponsors from the pharmaceutical industry comprising Astra Zeneca/BMS, Novo Nordisk, Merck, Sanofi Aventis and Bayer has provided an unrestricted grant to ApEHR for the conduct of this research.We thank professor Kristian Bolin for useful commenting.

\section{Conflicts of Interest}

Neither the Danish Diabetes Association nor the consortium of sponsors from the pharmaceutical industry has had any influence on the conduct of the study.

\section{Acknowledgements}

This study was conducted on behalf of the Danish Diabetes Association and supported by a PhD program at COHERE supported by the Danish Centre for Strategic Research in Type 2 Diabetes, DD2. We thank Mrs. Sabrina I. Imeroski for editorial assistance. We thank professor Kristian Bolin for useful commenting. 


\section{References}

[1] WorldHealthOrganization (2011) Global Status Report on Noncommunicable Diseases 2010_Description of the Global Burden of NCDs, Their Risk Factors and Determinants. World Health Organization.

[2] World Health Organization (2015) Diabetes Fact sheet. http://www.who.int/mediacentre/factsheets/fs312/en/

[3] European Diabetes Leadership Forum (2012) The Diabetes Epidemic and Its Impact on Europe.

[4] Association, A.D. (2013) Economic Costs of Diabetes in the U.S. in 2012. Diabetes Care, 36, 1033-1046. http://dx.doi.org/10.2337/dc12-2625

[5] Robert, H. and Blank, V.B. (2013) Comparative Health Policy. 4 Edition, Palgrave Macmillan, New York.

[6] Mayega, R.W., et al. (2013) Diabetes and Pre-Diabetes among Persons Aged 35 to 60 Years in Eastern Uganda: Prevalence and Associated Factors. PLoS ONE, 8, e72554. http://dx.doi.org/10.1371/journal.pone.0072554

[7] Ning, G. and Bloomgarden, Z. (2013) Diabetes in China: Prevalence, Diagnosis, and Control. Journal of Diabetes, 5, 372. http://dx.doi.org/10.1111/1753-0407.12088

[8] Bhowmik, B.A.F., My Diep, L., Binte Munir, S., Wright, E., Mahmood, S., Khan, A.K.A. and Hussain, A. (2013) Increasing Prevalence of Type 2 Diabetes in a Rural Bangladeshi Population: A Population Based Study for 10 Years. Diabetes and Metabolism Journal, 37, 46-53. http://dx.doi.org/10.4093/dmj.2013.37.1.46

[9] Green, A.(2008) Diabetes Mellitus i Danmark 1997-2006-Epidemiologiske Analyser. Institut for Sundhedstjenesteforskning, Odense, Denmark.

[10] Maruthur, N.M. (2013) The Growing Prevalence of Type 2 Diabetes: Increased Incidence or Improved Survival? Current Diabetes Reports, 13, 786-794. http://dx.doi.org/10.1007/s11892-013-0426-4

[11] Green, A.S.C., Jensen, P.B. and Emneus, M. (2015) Incidence, Morbidity, Mortality, and Prevalence of Diabetes in Denmark, 2000-2011: Results from the Diabetes Impact Study 2013. Dove Press, London.

[12] Gillies, C.L., Lambert, P.C., Abrams, K.R., Sutton, A.J., Cooper, N.J., Hsu, R.T., Davies, M.J. and Khunti, K. (2008) Different Strategies for Screening and Prevention of Type 2 Diabetes in Adults: Cost Effectiveness Analysis. BMJ, 336, 1180-1185. http://dx.doi.org/10.1136/bmj.39545.585289.25

[13] Fazeli Farsani, S., van der Aa, M.P., van der Vorst, M.M.J., Knibbe, C.A.J. and de Boer, A. (2013) Global Trends in the Incidence and Prevalence of Type 2 Diabetes in Children and Adolescents: A Systematic Review and Evaluation of Methodological Approaches. Diabetologia, 56, 1471-1488. http://dx.doi.org/10.1007/s00125-013-2915-z

[14] Patterson, C.C., Dahlquist, G.G., Gyürüs, E., Green, A. and Soltész, G. (2009)Incidence Trends for Childhood Type 1 Diabetes in Europe during 1989-2003 and Predicted New Cases 2005-20: A Multicentre Prospective Registration Study. The Lancet, 373, 2027-2033. http://dx.doi.org/10.1016/S0140-6736(09)60568-7

[15] Rosella, L.C., Lebenbaum, M., Fitzpatrick, T., O’Reilly, D., Wang, J., Booth, G.L., et al. (2015) Impact of Diabetes on Healthcare Costs in a Population-Based Cohort: A Cost Analysis. Diabetic Medicine, Epub ahead of Print.

[16] Sortsø, C., Green, A., Jensen, P.B. and Emneus, M. (2015) Societal Costs of Diabetes Mellitus in Denmark. Diabetic Medicine, In Preperation.

[17] Astolfi, R., Lorenzoni, L. and Oderkirk, J. (2012) A Comparative Analysis of Health Forecasting Methods. OECD, France, 121. http://dx.doi.org/10.1787/5k912j389bf0-en

[18] King, H., Aubert, R.E. and Herman, W.H. (1998) Global Burden of Diabetes, 1995-2025: Prevalence, Numerical Estimates, and Projections. Diabetes Care, 21, 1414-1431. http://dx.doi.org/10.2337/diacare.21.9.1414

[19] Bagust, A., Hopkinson, P.K., Maslove, L. and Currie, C.J. (2002) The Projected Health Care Burden of Type 2 Diabetes in the UK from 2000 to 2060. Diabetic Medicine, 19, 1-5. http://dx.doi.org/10.1046/j.1464-5491.19.s4.2.x

[20] Huang, E.S., Basu, A., O’Grady, M., Capretta, J.C., et al. (2009) Projecting the Future Diabetes Population Size and Related Costs for the US. Diabetes Care, 32, 2225-2229. http://dx.doi.org/10.2337/dc09-0459

[21] Mainous, A.G., Baker, R., Koopman, R.J.,et al. (2007) Impact of the Population at Risk of Diabetes on Projections of Diabetes Burden in the United States: An Epidemic on the Way. Diabetologia, 50, 934-940. http://dx.doi.org/10.1007/s00125-006-0528-5

[22] Tunceli, K., Zeng, H.W., Habib, Z.A. and Williams, L.K.(2009) Long-Term Projections for Diabetes-Related Work Loss and Limitations among US Adults. Diabetes Research and Clinical Practice, 83, e23-e25. http://dx.doi.org/10.1016/j.diabres.2008.11.004

[23] Green, A., Christansen, T., Björk, S., Kristensen, J.K., et al. (2006) Type 1 Diabetes in Denmark Year 2001.

[24] Green, A., Christansen, T., Björk, S., Kristensen, J.K., et al. (2006) Type 2 Diabetes in Denmark Year 2001. Odense.

[25] Thygesen, L.C. and Ersboll, A.K. (2011) Danish Population-Based Registers for Public Health and Health-Related Welfare Research: Introduction to the Supplement. Scandinavian Journal of Public Health, 39, 8-10. 
http://dx.doi.org/10.1177/1403494811409654

[26] Association, D.D. (2013) Project: Diabetes Impact Study 2013. 2015 14-SEP-2015 16-SEP-2015. http://www.diabetes.dk/fagfolk/diabetesforeningens-projekter-undersoegelser/projekt-diabetes-impact-study-2013.aspx

[27] Green, A., Sortsø, C., Jensen, P.B. and Emneus, M. (2015) Validation of the Danish National Diabetes Register. Journal of Clinical Epidemiology, 7, 5-15.

[28] Briggs, A., Claxton, K. and Sculpher, M. (2006) Decision Modelling for Health Economic Evaluation. Oxford University Press, New York.

[29] Denmark, S. (2015) Population Projection 2014-2040 (Database on the Internet). http://www.statistikbanken.dk/statbank5a/default.asp?w=979

[30] Ministeriet-Sundhedogforebyggelse. DRG-Leksikon, 2012. http://www.sum.dk/Sundhed/DRG-systemet/DRG-leksikon.aspx.

[31] Kristensen, T., Olsen, K.R., Sortsø, C., Ejersted, C., Thomsen, J.L. and Halling, A. (2013) Resources Allocation and Health Care Needs in Diabetescare in Danish GP Clinics. Health Policy, 113, 206-215. http://dx.doi.org/10.1016/j.healthpol.2013.09.006

[32] Yeaw, J., Lee, W.C., Aagren, M. and Christensen, T. (2012) Cost of Self-Monitoring of Blood Glucose in the United States among Patients on an Insulin Regimen for Diabetes. Journal of Managed Care Pharmacy, 18, 21-32.

[33] Association TDD (2010) http://www.diabetes.dk/aktuelt/nyheder/nyhedsarkiv/2010/for-faa-diabetikere-har-insulinpumpe.aspx

[34] Sundhedsstyrelsen. Type 2-Diabetes-Medicinsk teknologivurdering af screening, diagnostik og behandling. Danmark: Sundhedsstyrelsen, 2003.

[35] http://www.nettomedical.dk/category/koerestole-109/

[36] Russel, L., Suh, D. and Safford, M. (2005) Time Requirement or Diabetes Self-Management, Too Much for Many? Journal of Family Practice, 54, 52-56.

[37] Russel, L. (2009) Completing Costs, Patient's Time. Medical Care, 47, 89-93.

[38] Eng, D.S. and Lee, J.M. (2013) The Promise and Peril of Mobile Health Applications for Diabetes and Endocrinology. Pediatric Diabetes, 14, 231-238. http://dx.doi.org/10.1111/pedi.12034

[39] Edwards, D., Noyes, J., Lowes, L., Spencer, L.H. and Gregory, J.W. (2014) An Ongoing Struggle: A Mixed-Method Systematic Review of Interventions, Barriers and Facilitators to Achieving Optimal Self-Care by Children and Young People with Type 1 Diabetes in Educational Settings. BMC Pediatrics, 14, 228. http://dx.doi.org/10.1186/1471-2431-14-228

[40] Danske Regioner, F., Ministeriet for Sundhed og Forebyggelse (2012) Løbende offentliggørelse af produktivitet i sygehussektoren (VIII delrapport). Udviklingen fra 2010 til 2011.

[41] Denmark, S. (2012) Pleje- og ældreboliger 2012. Sociale forhold, sundhed og retsvæsen. 2012 16-SEP-2015. http://www.dst.dk/pukora/epub/Nyt/2012/NR668.pdf

[42] Caro, J.J., Briggs, A.H., Siebert, U. and Kuntz, K.M. (2012) Modeling Good Research Practices-Overview: A Report of the ISPOR-SMDM Modeling Good Research Practices Task Force-1. Value in Health, 15, 796-803. http://dx.doi.org/10.1016/j.jval.2012.06.012

\author{
Abbreviations \\ CG0: Complication group 0 (no complications) \\ CG1: Complication group 1 (minor complications) \\ CG2: Complication group 2 (minor complications) \\ M: Men \\ PIN: Danish Personal Identification Number \\ PP: Per person \\ PYRS: Patient Years \\ PWD: Patients with Diabetes \\ SD: Statistics Denmark \\ W: Women
}




\section{Supplementary Materials}

Table A.Grouping of diagnoses and interventions used for classifying hospital activities by complication states of relevance for diabetes, and with respect to diagnostic specificity for diabetes.

\begin{tabular}{|c|c|c|}
\hline Diagnosis or procedure & Qualifying for complication state ${ }^{a}$ & Specificity for diabetes ${ }^{\mathrm{b}}$ \\
\hline Diabetes in pregnancy, childbirth and the puerperium & 0 & 1 \\
\hline Diabetes, without indication of chronic complication & 0 & 1 \\
\hline Hypoglycaemiccoma NOS & 0 & 0 \\
\hline Screening for diabetic retinopathy & 0 & 1 \\
\hline Drug treatment or instruction specific for diabetes & 0 & 1 \\
\hline Acute myocardial infarction & 1 & 0 \\
\hline Diabetes with complication, not further specified & 1 & 1 \\
\hline Diabetes with complications in peripheral vascular system & 1 & 1 \\
\hline Diabetes with eye complication & 1 & 1 \\
\hline Diabetes with footulcer & 1 & 1 \\
\hline Diabetes with microangiopathy & 1 & 1 \\
\hline Diabetes with neurological complication & 1 & 1 \\
\hline Diabetes with peripheral angiopathy & 1 & 1 \\
\hline Diabetes with renal complication & 1 & 1 \\
\hline Diabetic cataract & 1 & 1 \\
\hline Diabetic polyneuropathy & 1 & 1 \\
\hline Diabetic retinopathy not otherwise specified & 1 & 1 \\
\hline Diseases of the lens & 1 & 0 \\
\hline Polyneuropathy & 1 & 0 \\
\hline Proliferative diabetic retinopathy & 1 & 1 \\
\hline Uraemia & 1 & 0 \\
\hline Simplex diabetic retinopathy & 1 & 1 \\
\hline Cataract, retinopathy in diabetes & 1 & 1 \\
\hline Diabetic angiopathy in extremities & 1 & 1 \\
\hline Diabetic nephropathy, Kimmelstiel-Wilson syndrom & 1 & 1 \\
\hline Neuropathy, diabetic polyneuritis, diabetes & 1 & 1 \\
\hline Amputation at or below ankle level & 1 & 0 \\
\hline Coronary bypass operation & 1 & 0 \\
\hline Surgery for eye complication & 1 & 0 \\
\hline Teatment of ulcer of lower limb & 1 & 0 \\
\hline Diabetes with gangraene & 2 & 1 \\
\hline Diabetes with multiple complications & 2 & 1 \\
\hline Diabetic maculopathy & 2 & 1 \\
\hline Dialysis & 2 & 0 \\
\hline Diseases of the retina & 2 & 0 \\
\hline Heart failure & 2 & 0 \\
\hline Kidney transplantation & 2 & 0 \\
\hline Renalfailure & 2 & 0 \\
\hline Stroke & 2 & 0 \\
\hline Blindness & 2 & 0 \\
\hline Diabetic gangraene & 2 & 1 \\
\hline Gangrena of lower limb & 2 & 0 \\
\hline Intracerebral haemorrhage & 2 & 0 \\
\hline Amputation above ankle level & 2 & 0 \\
\hline
\end{tabular}

${ }^{\mathrm{a}}$ Value indicates classification state $\left(0,1\right.$ or 2 , respectively). ${ }^{\mathrm{b}}$ Values 1 and 0 indicate that item is specific for diabetes and unspecific for diabetes, respectively. 
Table B.Prevalence, total attributable costs and cost per PYRS 2011, 2025 and 2040 in three epidemiological scenarios.

\begin{tabular}{|c|c|c|c|c|c|c|c|}
\hline Scenarios & & CORE & CORE & INTERMEDIATE & INTERMEDIATE & CONSTANT & CONSTANT \\
\hline Main results & 2011 & 2025 & 2040 & 2025 & 2040 & 2025 & 2040 \\
\hline Prevalence & 300.769 & 644.738 & 1.183 .630 & 564.781 & 862.623 & 516.239 & 660.102 \\
\hline Comp 0 & 166.327 & 372.443 & 708.091 & 320.497 & 504.314 & 270.745 & 320.276 \\
\hline Comp 1 & 57.415 & 123.738 & 219.485 & 112.333 & 171.215 & 106.545 & 139.486 \\
\hline Comp 2 & 77.027 & 148.557 & 256.055 & 131.951 & 187.094 & 138.949 & 200.340 \\
\hline Incidence & 29.451 & 46.756 & 62.694 & 34.289 & 35.967 & 34.289 & 35.967 \\
\hline Mortality & 11.714 & 16.139 & 23.443 & 14.246 & 17.125 & 21.080 & 29.281 \\
\hline Costs & 2011 & 2025 & 2040 & 2025 & 2040 & 2025 & 2040 \\
\hline Health care & 725.464 .495 & 1.431.166.663 & 2.455.206.345 & 1.286 .964 .483 & 1.842 .156 .831 & 1.315.790.252 & 1.850 .934 .097 \\
\hline Pharma & 149.953 .681 & 306.038 .534 & 532.748 .176 & 274.264.799 & 400.288 .479 & 267.676 .403 & 359.781 .970 \\
\hline Nursing & 849.715 .906 & 1.619.462.228 & 2.706.184.561 & 1.468.784.708 & 2.063.159.419 & 1.544.346.999 & 2.236 .535 .856 \\
\hline Prod & 1.750 .025 .792 & 3.064.095.305 & 4.923.289.744 & 2.746.838.024 & 3.698.946.354 & 3.127.797.930 & 4.207.509.369 \\
\hline Add & 761.956 .851 & 1.529.690.283 & 2.638.947.964 & 1.369 .600 .181 & 1.974.463.293 & 1.356.548.093 & 1.849 .550 .722 \\
\hline Total & 4.237.116.724 & 7.950.453.013 & 13.256.376.791 & 7.146.452.195 & 9.979.014.377 & 7.576.581.375 & 10.452 .804 .987 \\
\hline Costs & 2011 & 2025 & 2040 & 2025 & 2040 & 2025 & 2040 \\
\hline Comp 0 & 1.000 .175 .623 & 2.136.663.476 & 3.976.831.728 & 1.848.713.102 & 2.829.576.658 & 1.653.206.164 & 1.942 .921 .596 \\
\hline Comp 1 & 780.825 .699 & 1.587.383.184 & 2.735.883.493 & 1.452 .635 .301 & 2.152.000.515 & 1.486.812.323 & 1.966 .885 .574 \\
\hline Comp 2 & 2.456.115.402 & 4.226.406.354 & 6.543.661.570 & 3.845.103.792 & 4.997.437.204 & 4.436.562.888 & 6.542.997.816 \\
\hline Total & 4.237.116.724 & 7.950.453.013 & 13.256.376.791 & 7.146.452.195 & 9.979.014.377 & 7.576.581.375 & 10.452 .804 .987 \\
\hline Cost per PYRS & 2011 & 2025 & 2040 & 2025 & 2040 & 2025 & 2040 \\
\hline Health care & 2.412 & 2.220 & 2.074 & 2.279 & 2.136 & 2.549 & 2.804 \\
\hline Pharma & 499 & 475 & 450 & 486 & 464 & 519 & 545 \\
\hline Nursing & 2.825 & 2.512 & 2.286 & 2.601 & 2.392 & 2.992 & 3.388 \\
\hline Prod & 5.819 & 4.752 & 4.159 & 4.864 & 4.288 & 6.059 & 6.374 \\
\hline Add & 2.533 & 2.373 & 2.230 & 2.425 & 2.289 & 2.628 & 2.802 \\
\hline Total & 14.088 & 12.331 & 11.200 & 12.653 & 11.568 & 14.676 & 15.835 \\
\hline \multicolumn{8}{|l|}{ Cost per PYRS } \\
\hline Comp 0 & 6.013 & 5.737 & 5.616 & 5.768 & 5.611 & 6.106 & 6.066 \\
\hline Comp 1 & 13.600 & 12.829 & 12.465 & 12.932 & 12.569 & 13.955 & 14.101 \\
\hline Comp 2 & 31.887 & 28.450 & 25.556 & 29.140 & 26.711 & 31.929 & 32.659 \\
\hline Total & 14.088 & 12.331 & 11.200 & 12.653 & 11.568 & 14.676 & 15.835 \\
\hline CostsComp 0 & 2011 & 2025 & 2040 & 2025 & 2040 & 2025 & 2040 \\
\hline Health care & 89.858 .530 & 192.519 .334 & 357.882 .722 & 167.209 .450 & 254.934 .374 & 146.323 .763 & 173.757.001 \\
\hline Pharma & 49.838.798 & 110.062 .768 & 207.478.714 & 95.344 .235 & 147.955 .413 & 81.928.854 & 96.563 .562 \\
\hline Nursing & 42.624 .350 & 94.604 .864 & 179.036 .012 & 82.877 .432 & 130.048 .675 & 73.656 .667 & 91.717 .861 \\
\hline Prod & 570.851 .210 & 1.193.708.678 & 2.203.162.563 & 1.030 .274 .736 & 1.561 .946 .494 & 944.518 .912 & 1.100 .545 .460 \\
\hline Add & 247.002 .735 & 545.767 .832 & 1.029 .271 .717 & 473.007 .250 & 734.691 .702 & 406.777 .968 & 480.337 .711 \\
\hline Total & 1.000 .175 .623 & 2.136.663.476 & 3.976 .831 .728 & 1.848.713.102 & 2.829.576.658 & 1.653.206.164 & 1.942.921.596 \\
\hline \multicolumn{8}{|l|}{ CostsComp 1} \\
\hline Health care & 140.219 .673 & 302.987 .736 & 535.364 .206 & 276.895 .072 & 420.743 .614 & 265.840 .227 & 352.108 .316 \\
\hline Pharma & 41.115 .818 & 87.645 .991 & 152.374 .975 & 80.431 .870 & 120.556 .747 & 78.113 .986 & 104.168 .247 \\
\hline Nursing & 132.137 .580 & 279.397.935 & 486.999.832 & 256.937.075 & 387.705 .039 & 251.399.983 & 339.344 .222 \\
\hline Prod & 342.957 .246 & 651.973 .536 & 1.099 .551 .688 & 594.900 .265 & 857.994 .243 & 655.209 .285 & 856.531 .503 \\
\hline Add & 124.395 .382 & 265.377.986 & 461.592 .792 & 243.471 .020 & 365.000 .871 & 236.248 .842 & 314.733.286 \\
\hline Total & 780.825.699 & 1.587.383.184 & 2.735.883.493 & 1.452 .635 .301 & 2.152.000.515 & 1.486.812.323 & 1.966.885.574 \\
\hline \multicolumn{8}{|l|}{ Costs Comp 2} \\
\hline Health care & 495.386 .292 & 935.659 .594 & 1.561.959.417 & 842.859 .962 & 1.166 .478 .842 & 903.626 .263 & 1.325 .068 .780 \\
\hline Pharma & 58.999 .065 & 108.329.774 & 172.894 .487 & 98.488 .694 & 131.776 .319 & 107.633 .562 & 159.050.161 \\
\hline Nursing & 674.953.976 & 1.245.459.429 & 2.040.148.717 & 1.128.970.201 & 1.545 .405 .705 & 1.219.290.350 & 1.805 .473 .773 \\
\hline Prod & 836.217.336 & 1.218.413.092 & 1.620 .575 .493 & 1.121 .663 .023 & 1.279.005.617 & 1.528.069.732 & 2.250 .432 .405 \\
\hline Add & 390.558 .733 & 718.544 .466 & 1.148 .083 .456 & 653.121 .912 & 874.770 .720 & 713.521 .284 & 1.054.479.725 \\
\hline Total & 2.456.115.402 & 4.226.406.354 & 6.543.661.570 & 3.845.103.792 & 4.997.437.204 & 4.436.562.888 & 6.542.997.816 \\
\hline
\end{tabular}


Table C.Results of the economic potentials: investments.

\begin{tabular}{|c|c|c|}
\hline Hypotheses & \multicolumn{2}{|l|}{ Core Scenario } \\
\hline Description & \multicolumn{2}{|c|}{ Continuation of observed epidemiological trends and 2011 cost structure } \\
\hline & 2025 & 2040 \\
\hline \multirow[t]{4}{*}{ Total costs } & $€ 7,934,796,435$ & $€ 13,230,271,423$ \\
\hline & \multicolumn{2}{|c|}{ Core adjusted-H1 } \\
\hline & \multicolumn{2}{|c|}{ Investments in primary care (annual +5\%) } \\
\hline & 2025 & 2040 \\
\hline Total costs & $€ 7,979,606,895$ & $€ 13,459,970,529$ \\
\hline \multirow[t]{4}{*}{ cost difference 2011 Core } & $-€ 44,810,460$ & $-€ 229,699,106$ \\
\hline & \multicolumn{2}{|c|}{ Core adjusted-H2 } \\
\hline & \multicolumn{2}{|c|}{ Investments in pharmaceuticals (annual $+2.5 \%$ ) } \\
\hline & 2025 & 2040 \\
\hline Total costs & $€ 8,060,933,449$ & $€ 13,786,645,242$ \\
\hline \multirow[t]{4}{*}{ cost difference 2011 Core } & $-€ 126,137,015$ & $-€ 556,373,819$ \\
\hline & \multicolumn{2}{|c|}{ Core adjusted-H3a } \\
\hline & \multicolumn{2}{|c|}{ Investments in secondary prevention-SMBG (annual $+2.5 \%$ ) } \\
\hline & 2025 & 2040 \\
\hline Total costs & $€ 7,986,769,133$ & $€ 13,466,526,139$ \\
\hline \multirow{4}{*}{ cost difference 2011 Core } & $-€ 51,972,699$ & $-€ 236,254,715$ \\
\hline & \multicolumn{2}{|c|}{ Core adjusted-H3b } \\
\hline & \multicolumn{2}{|c|}{ Investments in secondary prevention-Patient education (annual +2.5\%) } \\
\hline & 2025 & 2040 \\
\hline Total costs & $€ 7,954,901,428$ & $€ 13,321,575,284$ \\
\hline \multirow[t]{4}{*}{ cost difference 2011 Core } & $-€ 20,104,993$ & $-€ 91,303,861$ \\
\hline & \multicolumn{2}{|c|}{ Core adjusted-H3c } \\
\hline & \multicolumn{2}{|c|}{ Investments in secondary prevention—Patients' own time (annual +2.5\%) } \\
\hline & 2025 & 2040 \\
\hline Total costs & $€ 8,229,416,849$ & $€ 14,562,020,821$ \\
\hline cost difference 2011 Core & $-€ 294,620,415$ & $-€ 1,331,749,397$ \\
\hline
\end{tabular}

Table D.Results of the economic potentials: efficiency improvements.

\begin{tabular}{|c|c|c|}
\hline Hypotheses & \multicolumn{2}{|l|}{ Core } \\
\hline Description & \multicolumn{2}{|c|}{ Continuation of observed epidemiological trends and 2011 cost structure } \\
\hline & 2025 & 2040 \\
\hline \multirow[t]{4}{*}{ Total costs } & $€ 7,934,796,435$ & $€ 13,230,271,423$ \\
\hline & \multicolumn{2}{|c|}{ Core adjusted-H4a } \\
\hline & \multicolumn{2}{|c|}{ Effiency improvements in health care (annual -1\%) } \\
\hline & 2025 & 2040 \\
\hline Total costs & $€ 7,747,319,738$ & $€ 12,610,749,158$ \\
\hline \multirow[t]{4}{*}{ cost difference 2011 Core } & $€ 187,476,697$ & $€ 619,522,265$ \\
\hline & \multicolumn{2}{|c|}{ Core adjusted-H4b } \\
\hline & \multicolumn{2}{|c|}{ Efficiency improvements in nursing (annual -1\%) } \\
\hline & 2025 & 2040 \\
\hline Total costs & $€ 7,722,653,826$ & $€ 12,547,419,820$ \\
\hline \multirow[t]{4}{*}{ cost difference 2011 Core } & $€ 212,142,608$ & $€ 682,851,603$ \\
\hline & \multicolumn{2}{|c|}{ Core adjusted-H5 } \\
\hline & \multicolumn{2}{|c|}{ Reduced usage of nursing services (annual -2.5\%) } \\
\hline & 2025 & 2040 \\
\hline Total costs & $€ 7,452,435,378$ & $€ 11,825,506,131$ \\
\hline \multirow[t]{4}{*}{ cost difference 2011 Core } & $€ 482,361,057$ & $€ 1,404,765,292$ \\
\hline & \multicolumn{2}{|c|}{ Core adjusted-H6 } \\
\hline & \multicolumn{2}{|c|}{ Reduced usage of secondary care (annual $-2.5 \%$ ) } \\
\hline & 2025 & 2040 \\
\hline Total costs & $€ 7,522,166,828$ & $€ 11,994,126,929$ \\
\hline \multirow[t]{4}{*}{ cost difference 2011 Core } & $€ 412,629,607$ & $€ 1,236,144,494$ \\
\hline & \multicolumn{2}{|c|}{ Core adjusted-H7 } \\
\hline & \multicolumn{2}{|c|}{ Reduced productivity loss among patients in CG0 (annual $-2.5 \%$ ) } \\
\hline & 2025 & 2040 \\
\hline Total costs & $€ 7,655,644,969$ & $€ 12,332,342,573$ \\
\hline cost difference 2011 Core & $€ 279,151,466$ & $€ 897,928,850$ \\
\hline
\end{tabular}

